\title{
A CONSTRUÇÃO DO PERSONAGEM ARTHUR POR MEIO DE SUA CONEXÃO COM A COZINHA NO ROMANCE THE SOLID MANDALA, DE PATRICK WHITE
}

\section{ARTHUR'S CHARACTER CONSTRUCTION THROUGH HIS CONNECTION WITH THE KITCHEN IN PATRICK WHITE'S NOVEL THE SOLID MANDALA}

STEFANI, Monica ${ }^{1}$

\begin{abstract}
RESUMO: Este artigo apresenta a relação da personagem Arthur com as atividades na cozinha, mais precisamente a fabricação de pão e manteiga, como um modo de favorecimento de sua construção narrativa (seguindo as proposições da holandesa Mieke Bal) no romance The Solid Mandala (1966), do escritor australiano Patrick White, prêmio Nobel de Literatura em 1973. A partir de trechos selecionados, demonstramos como se dá essa atividade na trama e todas as repercussões advindas delas, destacando a socialização entre personagens, mas principalmente a constituição identitária de Arthur: é ele quem tem a "missão" de fazer esses produtos que, inevitavelmente, vão sustentar a ele e a seu irmão até o final de suas vidas (desse modo negando a "trivialidade" da atividade). Se esse romance demonstra o poder que a literatura possui de transcender a nossa mera existência em qualquer espaço, podemos fazer a mesma analogia com a culinária: a literatura está para a cozinha assim como a cozinha está para a literatura, alimentando seres.
\end{abstract}

PALAVRAS-CHAVE: Literatura Australiana, Patrick White, Cozinha, Personagem, Narrativa, Tradução.

ABSTRACT: This paper analyses the relationship of the character Arthur with his activities in the kitchen, more precisely the baking of bread and churning of butter, as a way to favour his narrative construction in the novel The Solid Mandala (1966), by the Australian writer Patrick White, who won the Nobel Prize in Literature in 1973. From selected excerpts, we demonstrate how these activities takes place in the plot and all the repercussions coming from them, highlighting socialization among the characters, but mainly the identity formation of Arthur: he is the one who has the "mission" to

\footnotetext{
${ }^{1}$ Doutora em Letras - Literaturas de Língua Inglesa pela Universidade Federal do Rio Grande do Sul (UFRGS) e Professora Adjunta de Literaturas de Língua Inglesa na Universidade Federal de Santa Maria (UFSM). E-mail: monicastefani31@gmail.com
}

Jangada | nr. 11, jan/jun, 2018 | ISSN 2317-4722 123 | Pá g ina 


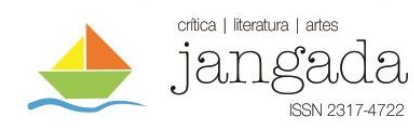

make these products which, inevitably, will sustain him and his brother until the end of their lives (thus denying the "triviality" of such works). If this novel proves how powerful literature is in making us transcend our mere existence in any space, we can make an analogy with cooking: as literature is to cooking so cooking is to literature, nurturing beings.

KEYWORDS: Australian Literature, Patrick White, Kitchen, Cooking.

Patrick White continua sendo o único australiano vencedor do prêmio Nobel de Literatura (1973). Embora tenha nascido em Londres, em 1912, voltou para a Austrália com seus pais (que haviam passado 6 meses em lua-de-mel pela Europa) e permaneceu no país até seus 12 anos, quando foi enviado novamente para a Inglaterra, onde supostamente receberia uma educação imperial (i.e., mais adequada do que na colônia) em uma boarding school. Após seus estudos, decidiu retornar para a Austrália, então como um jovem de 17 anos que se odiava, para trabalhar como jackeroo - isto é, um jovem que trabalha na criação de ovelhas ou gado para ganhar experiência e prática para posteriormente se tornar proprietário, supervisor ou gerente. Durante seu tempo livre, ele colocava em prática a sua paixão: a escrita. Seus pais acreditavam que Patrick fosse seguir a carreira diplomática. Na visão deles, a Austrália não seria capaz de proporcionar uma educação de qualidade, assim, ele retorna à Inglaterra, desta vez para cursar Letras (Francês e Alemão) em Cambridge e, depois de sua graduação, seguir sua vocação: ser escritor. Com este background um tanto resumido, com destaque para suas inúmeras idas e vindas entre o mundo da Metrópole (Inglaterra e tida como "Home" em seus escritos) e a colônia (Sydney), conseguimos entender um pouco melhor a trama do romance The Solid Mandala, publicado em 1966 (que, apesar de ainda não ter sido comercialmente traduzido para o português do Brasil ${ }^{2}$, possui a tradução mais recente em espanhol publicada em 2016 pela editora El Hilo de Ariadna, de Buenos Aires). O sentimento de White em relação aos dois países fica no "meio-termo": ele se sente um londrino³ (MARR, 1995, p. 536).

O foco da história é a relação entre os irmãos gêmeos Arthur e Waldo Brown, filhos do casal inglês George Brown e Anne Quantrell. A família migra da Inglaterra para a

\footnotetext{
${ }^{2}$ Para mais informações acerca da tradução de The Solid Mandala em português do Brasil, veja a tese intitulada The Translation of Patrick White's The Solid Mandala into Brazilian Portuguese: an Analysis Based on Social, Historical and Cultural Aspects (UFRGS, 2016), disponível em: http://www.lume.ufrgs.br/bitstream/handle/10183/156966/001016793.pdf?sequence=1

3 "I feel what I am, I don't feel particularly Australian. I live here and work here. A Londoner is what I think I am at heart but my blood is Australian and that's what gets me going” (MARR, 1995, p. 536).
} 


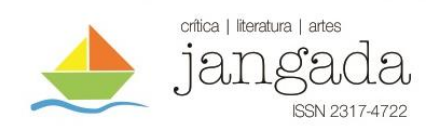

Austrália, deixando para trás uma série de coisas, entre elas seus valores e suas visões de mundo, que começam a ser confrontadas em um novo território: o fim da rua (Terminus Road) em Sarsaparilla, o subúrbio fictício de Sydney criado por Patrick White para servir de cenário para todas essas transformações.

Estruturalmente, o romance é dividido em 4 capítulos. No primeiro, intitulado "In the Bus" (No ônibus), a história tem a perspectiva presente (que seria dos anos 1960), com a Sra. Poulter (vizinha dos Brown em Sarsaparilla) conversando com a Sra. Dun no ônibus, e avistando os irmãos Brown, já idosos, caminhando de mãos dadas na rua. No segundo capítulo, intitulado "Waldo", é pelo ponto de vista do personagem homônimo que a história nos é contada, com inúmeros flashbacks; no terceiro capítulo, intitulado “Arthur”, é a vez de o ponto de vista de Arthur aparecer, para esclarecer alguns pontos apresentados no capítulo anterior (de fato, podemos sobrepor os acontecimentos, e ali percebemos a maestria de White ao compor esse romance); finalmente, o capítulo final, "Mrs Poulter and the Zeitgeist" (A Sra. Poulter e o Zeitgeist), nos apresenta a voz da Sra. Poulter, fechando o ciclo da narrativa.

Como parte das dicotomias que caracterizam o uso de gêmeos na Literatura, o caso dos irmãos Brown não poderia ser diferente. Waldo seria o "intelectual” da família, mas sua vida de aparências é uma sucessão de decepções e paradoxos: cercado de livros (trabalha em meio a eles na Biblioteca Municipal de Sydney), não consegue apreciar um poema ou mesmo devidamente ler alguma obra literária, sequer escrever uma. Mas não por algum tipo de deficiência ou impossibilidade: por excesso de orgulho e pela falta de qualquer tipo de emoção em sua vida. Segundo o próprio Patrick White, sua incapacidade de perdoar seria "um dos seus piores defeitos - muito Waldo em mim $^{4}$ " (MARR, 1995, p. 449).

Arthur, por sua vez, aparece com uma simplicidade de vida (e que transparece na sua linguagem) e de pensamento que cativa justamente por significar muito mais do que formalidades de discurso, demonstrando a preponderância de suas emoções, de sua sensibilidade, intuição e humildade, de seu dom artístico (sua dança é uma das cenas memoráveis do romance), e de seu amor.

Outros personagens de destaque são Dulcie Feinstein, a amiga dos gêmeos (e que chega a ser vista como um potencial partido por parte de Waldo); os pais da menina, os Feinstein, judeus que vivem em Sydney; e o Sr. e a Sra. Allwright, os donos do armazém onde Arthur trabalha.

\footnotetext{
${ }^{4}$ No original em inglês: "I am unforgiving. It is one of my worst faults - too much Waldo in me" (MARR, 1995, p. 449).

Jangada | nr. 11, jan/jun, 2018 | ISSN 2317-4722

125 | P á g in a
} 
Após este breve resumo acerca da trama do romance The Solid Mandala, vamos enfocar a importância das atividades na cozinha no percurso narrativo de construção do personagem Arthur, de certa forma evidenciando aspectos da vida de Patrick White.

\section{PATRICK WHITW E O "SACRAMENTO DA COMIDA"}

Elementos autobiográficos inevitavelmente aparecem em toda a obra de Patrick White. No caso de The Solid Mandala, os elementos estão mais especificamente relacionados ao modo de vida que ele levava em Sydney, marcando um período de mudança: quando saiu de sua residência em Castle Hill - onde ele e seu parceiro Manoly Lascaris aravam a terra, cultivavam alimentos e cuidavam dos animais - para Centennial Park, subúrbio de Sydney. White finalizou o primeiro rascunho de The Solid Mandala quinze dias após ter se mudado para a nova casa. Logo, perceber essa atmosfera de mudança (não apenas da família Brown, mas também dos Poulter e dos Feinstein) é um tanto compreensível.

Quanto ao hábito de cozinhar, isso não era segredo para Patrick White, que era conhecido por gostar da tarefa e inclusive destacava a combinação das duas atividades. Isso certamente se reflete na construção da identidade do personagem Arthur, que, além de seus afazeres na cozinha, se torna quem é por sua oposição a Waldo.

Convém ressaltar que todos os excertos utilizados neste trabalho foram retirados da tradução (ainda não publicada) feita como parte do doutorado em Estudos Literários (Estudos de Tradução - Literaturas de Língua Inglesa) na Universidade Federal do Rio Grande do Sul (UFRGS), em 2016. No seguinte trecho conseguimos visualizar como se dá a conexão entre literatura e cozinha no romance, o que ganha contornos religiosos, de ritual; nas palavras da Sra. Musto, quando perguntada sobre a função da boca:

Para que nossas bocas são dadas? É, eu sei - comida. Adorável, também. Ao alcance de todos em um país como a Austrália. Dê-me um bom pedaço de pastrame, com uma bela fatia de gordura amarela, e uma cebola fervida. Ooh, delícia! Há, claro, outras coisas além disso. Mas nunca esqueça uma ao lembrar a outra. Como eu disse ao Arcebispo, não vale, nunca, jamais, nem mesmo para um evangélico, negligenciar completamente a carne. O Arcebispo era da minha opinião. Mas Ela - Ela - Ela não é apenas uma pobre empreendedora, ela está claramente passando fome para fazer uma 


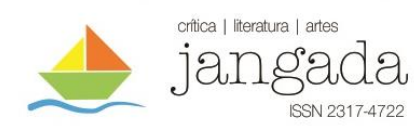

passagem confortável para o outro lado. Como eu não hesitei em falar pra ela. Mas como estava dizendo - o que estava dizendo? A conversa é o principal propósito para o qual essa pequena fenda foi nos dada - se comunicar em palavras. Nos dizem: no começo a Palavra já existia. O que meio que prova isso, não? (WHITE, 1974, tradução minha) ${ }^{5}$.

Se neste trecho já temos a conexão com a religião, com o fato de as refeições serem alvo de agradecimentos, de orações (e também de pecados capitais, afinal, a gula é um deles), em seguida Patrick White nos presenteia com outro trecho, no qual percebemos a entrada da Sra. Poulter na história. Com seu forte apego à religião, para ela sua caridade tem relação estreita com o ato de cozinhar (ou mesmo com a busca de ingredientes para realizar a ação), além de representar uma forma de socialização entre vizinhos, por mais cliché que isso possa parecer:

\begin{abstract}
A Sra. Poulter em pessoa começou a atravessar a rua. Ela pedia emprestado uma xícara de açúcar, uma xícara de arroz. Ela era a mulher de pele corada, jovem e decente que eles conheceram, que colocou um chapéu vermelho corajoso para caminhar por Terminus Road para os Allwright ou para o correio. Algumas vezes Arthur levava as compras em casa para ela, algumas vezes se era hora de fechar, eles caminhavam juntos, Arthur levando os sacos de papel marrom e os pacotes de jornal. Ela parecia começar a gostar dele, ou pelo menos ela não se importava, como algumas mulheres faziam.

Desde o começo a Sra. Poulter deu a impressão de querer fazer um ato de caridade.

- Se você tá doente, sabe, vocês só nos dão um grito, Sra. Brown, e eu venho pro outro lado e faço o que posso. Sentar com você à noite, ou algo assim. Ou se for os homens, Bill vem. Acho que Bill vem - ela foi cuidadosa para acrescentar.
\end{abstract}

\footnotetext{
5 “'Yairs, I know - food. Lovely, too. Within everybody's reach in a country like Australia. Give me a good lump of corned beef, with a nice slice of yellow fat, and a boiled onion. Ooh, scrumptious! There are, of course, other things besides. But never forget one in remembering the other. As I said to the Archbishop, it doesn't pay, never ever, not even an evangelical, to neglect the flesh altogether. The Archbishop was of my opinion. But She - She - She's not only a poor doer, she's clearly starving 'erself to make sure of a comfy passage to the other side. As I didn't hesitate to tell 'er. But as I was saying - what was I saying? Conversation is the prime purpose this little slit was given us for - to communicate in words. We are told: in the beginning was the Word. Which sort of proves, don't it?" (WHITE, 1974, p. 84).
} 


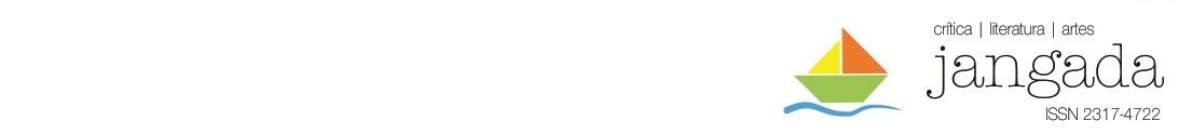

Waldo sabia como este tipo de coisa envergonhava sua mãe ${ }^{6}$ (WHITE, 1974, tradução minha).

Aqui a vergonha da mãe dos gêmeos não é pelo ato em si, mas pelo cunho religioso por eles detectado nessas atividades. O narrador do capítulo "Waldo" faz essa constatação mais uma vez: de que a Sra. Poulter via seu ato de caridade como uma forma de adoração a Deus, como algo misterioso e, acima de tudo, sagrado:

A Sra. Poulter, que tinha fé também na comida, trazia pratos para George Brown. Isso divertia a Mamãe.

- Aqui está um pudim de macarrão, Sr. Brown - a Sra. Poulter poderia dizer, abaixando a bacia para ele olhar dentro. - Bom - ela persuadiu. - Noz-moscada em cima. Você deve comer, sabe, para manter sua força.

Era mais do que um conselho. Aquilo, também, ela tentou transformar em um mistério.

- Fazendo um sacramento da comida. "Coma" é o que ela gostaria de dizer - disse Papai, rindo de sua própria brincadeira à custa das Igrejas e da Sra. Poulter ${ }^{7}$ (WHITE, 1974, tradução minha).

O excerto começa e termina com referências de deboche à fé da Sra. Poulter, embora as guloseimas preparadas por ela fossem apreciadas por George Brown, o pai "iluminista", que via na Austrália uma "terra sem sombras" e que havia se decepcionado com a sua fé na Igreja Batista.

\footnotetext{
${ }^{6}$ No original: "Mrs Poulter herself began to come across the road. She borrowed a cup of sugar, a cup of rice. She was the high-complexioned decent young woman they got to know, who put on a brave red hat to walk up Terminus Road to Allwrights' or the post-office. Sometimes Arthur brought the orders home for her, sometimes if it was closing time, they walked down together, Arthur carrying the brown-paper bags and the newspaper parcels. She seemed to take to him, or at least she didn't mind, as some women did. From the beginning Mrs Poulter gave the impression of wanting to perform some charitable act. "If you was ever sick, you know, you'd only have to give us a shout, Mrs Brown, and I'd come across and do what I could. Sit with you at night, or anything like that. Or if it was the men, Bill would. I think Bill would," she was careful to add. Waldo knew how this sort of thing embarrassed their mother (WHITE, 1974, p. 141).

${ }^{7}$ No original: "Mrs Poulter, who had faith also in food, used to bring dishes to George Brown. It amused Mother. "Here is a macaroni pudding, Mr Brown," Mrs Poulter might say, lowering the basin for him to look inside. "Nice," she coaxed. "Nutmeg on the top. You must eat, you know, to keep your strength up." It was more than advice. That, too, she tried to turn into a mystery. "Making a sacrament of food. 'Take eat' is what she would like to say," said Dad, laughing for his own joke at the expense of the Churches and Mrs Poulter" (WHITE, 1974, p. 159-160).
}

Jangada | nr. 11, jan/jun, 2018 | ISSN 2317-4722 128 | Pá g ina 


\section{1 jangada}

Essa interconexão entre literatura e cozinha aparece novamente no capítulo "Waldo", na seguinte frase: "Até ele ouvir Arthur, livros caindo no chão da cozinha; Arthur não gostava dos livros ${ }^{8 "}$ (WHITE, 1974, tradução minha).

Como parte da metodologia de seleção dos trechos para análise a fim de avaliar e/ou destacar a importância da culinária para a construção da identidade do personagem Arthur no romance The Solid Mandala, resolvemos buscar palavras-chave relacionadas aos hábitos das personagens no seu novo local no mundo, a saber, a Austrália. Começamos pensando em comidas típicas desse universo, e escolhemos os "rock-cakes" mencionados por Arthur logo no início do capítulo "Waldo" (lembrando seu ponto de vista dominante), quando os irmãos gêmeos, ainda crianças, estavam na expectativa de receber a visita das senhoritas Dallimores:

Mamãe disse que faria algumas broinhas, e talvez alguns de seus rock-cakes.

- Aah, siiim! - disse Arthur. - Os rock-cakes, Mãe!

Ele gostava dos cristais de açúcar por cima deles ${ }^{9}$ (WHITE, 1974, tradução minha).

Em termos de tradução, esse tipo de doce também aparece na série Harry Potter e ganhou a tradução de "bolinhos do Hagrid ${ }^{10 "}$. Todavia, destacamos aqui o fato de Arthur ser o personagem que lembra esses pequenos prazeres, isto é, os bolinhos preparados pela mãe, e as ocasiões sociais em que eles eram saboreados. Não é à toa que Arthur inevitavelmente deixa uma impressão positiva nas Dallimores, não apenas pelo destaque do sabor do doce (por ser algo feito pela mãe), mas pela possibilidade também de brincadeira (a atmosfera de volta no tempo, de infância evocada pelo narrador, chamando a atenção para o açúcar na cobertura do doce): esse toque simples conecta as experiências sensoriais do paladar e da visão, $\operatorname{logo}$ transparecendo ao leitor a alegria na personalidade de Arthur.

Outro tópico relacionado à tradução do romance está no seguinte trecho, com "mutton flaps":

$\mathrm{Ou}$ algumas vezes eles instigavam o destino, começavam a rechear um matambre de fraldas de carneiro, com os espetos de alumínio curvados

\footnotetext{
${ }^{8}$ No original: "Until he would hear Arthur, books falling on the kitchen floor; Arthur had not cared for books" (WHITE, 1974, p. 33).

${ }^{9}$ No original: "Mother said she would bake some scones, and perhaps a few of her rock-cakes. 'Ooh, yeees!' said Arthur. 'The rock-cakes, Mum!' He liked the sugar-crystals on them” (WHITE, 1974, p. 49).

${ }^{10}$ Para mais detalhes sobre a tradução escolhida, ver Stefani (2016).
} 


\section{1 jangada}

sempre adquirindo formas novas, ou jorrando no chão, à medida que as mãos lutavam para conter uma escultura de massa, ou torturar a morta à submissão ${ }^{11}$ (WHITE, 1974, tradução minha).

Nesta parte, percebemos como os hábitos alimentares contribuem para a descrição das personagens, e aqui utilizamos inclusive as palavras do próprio Patrick White para justificar suas escolhas lexicais no romance, que remetem à literatura como forma de representação social. Quem fez o questionamento quanto ao que viria a ser "mutton flaps" foi a tradutora do romance em sueco, Ingegärd Martinell. Patrick White, muito solícito, respondeu que era um prato um tanto gorduroso (pois era feito com as fraldas, que são uma parte da carne de carneiro que não é nobre) e que sinalizava a situação econômica precária da família Brown (MARR, 1995).

De fato, retomamos aqui o que Peter Newmark propõe em seus estudos sobre tradução: a relevância (e a dificuldade de tradução) de elementos relacionados à culinária de um determinado local, justamente por isso ser uma representação única e especial de uma cultura nacional; assim, os termos relacionados a comida são alvo da "maior variedade de procedimentos de tradução ${ }^{12 "}$ (NEWMARK, 1988, p. 97, tradução minha). Neste caso, optamos no português brasileiro por "matambre de fraldas de carneiro".

Procurando no texto original em inglês pelas ocorrências da palavra "kitchen" (cozinha), semanticamente atrelada à ideia de culinária, chegamos a 21. Não vamos abordar todas elas aqui, apenas as com os contextos mais relevantes. De fato, a cozinha transcende o mero aspecto de cenário, isto é, o local onde a história transcorre, transformando-se em um ponto de conversas entre a Sra. Poulter e Arthur:

Logo depois da chegada deles ele havia cruzado a rua para conversar com a mulher na cabana de ferro, para perguntar a ela entre muitas outras coisas, por que eles estavam vivendo em Terminus Road. Se as respostas dela variavam, ele aceitava a variedade; havia várias respostas para a maioria das perguntas. Ele tomava como certo que ele seria permitido se agachar fora da

\footnotetext{
${ }^{11}$ No original: "Or sometimes they would tempt fate, they would join in stuffing a mutton flap, with the old bent aluminium skewers always taking on fresh shapes, or raining on the floor, as hands fought to contain a sculpture of dough, or torture dead meat into submission. As they slapped and pinned, during their joint effort, they might begin to laugh, probably for different reasons. At least they had the meat in common. While the skewers threatened to pierce their hands (WHITE, 1974, p. 210).

${ }^{12}$ No original: "food terms are subjected to the widest variety of translation procedures" (NEWMARK, 1988, p. 97).
} 


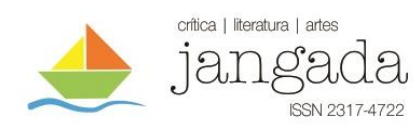

cabana dela loroteando, e finalmente, quando foi construída, ele se intrometia na cozinha dela, embora somente quando o marido dela não estava lá. A razão para isso era tão óbvia. O Sr. Poulter não gostava dele ${ }^{13}$ (WHITE, 1974, tradução minha).

Aqui já notamos o tom de "desconfiança" do Sr. Poulter em relação à presença constante de Arthur na vida do casal e, em específico, na cozinha. A partir dos resultados encontrados, estabelecemos uma conclusão importante: na maioria das ocorrências, há o envolvimento de Arthur, seja sozinho, seja em companhia de sua mãe ou da Sra. Poulter ou mesmo da Sra. Feinstein, na cozinha. Se seguirmos o que postula a holandesa Mieke Bal em seus trabalhos sobre narratologia:

As relações com os outros também a ajudam a construir a imagem de um personagem. A relação do personagem com ele mesmo em uma fase anterior também pertence a essa categoria. Essas relações tendem a ser processadas em semelhanças e contrastes. [...] As mudanças e transformações pelas quais um personagem passa algumas vezes alteram toda a configuração de personagem conforme observado durante a análise de relações mútuas ${ }^{14}$ (BAL, 2009, p. 127, tradução minha).

Percebemos que, além do contraste com Waldo, as atividades da Sra. Poulter na cozinha acabam levando à construção de um relacionamento forte com Arthur, pela semelhança de interesses. Assim, são criados dois polos na história: o dos conservadores, representados por Waldo e sua mãe; e o dos altruístas, que veem no ato de cozinhar uma forma de estabelecer laços de amizade e de caridade. Sabendo da importância que a Sra. Poulter adquire na narrativa tempos depois, o ato de cozinhar é justamente o que dá início a essa relação que, já aos olhos da mãe (e de Waldo), não caía bem.

\footnotetext{
${ }^{13}$ No original: "Soon after their arrival he had gone across the road to speak to the woman in the iron hut, to ask her among many other things, why they were living down Terminus Road. [...] He took it for granted he would be allowed to squat outside her hut yarning, and eventually, when it was built, he used to barge into her kitchen, though only when her husband wasn't there. The reason for that was too obvious. Mr Poulter didn't like him" (WHITE, 1974, p. 256-257).

${ }^{14}$ No original: "relations with others also help to build the image of a character. The character's relation to itself in an earlier phase also belongs to this category. These relations tend to be processed into similarities and contrasts. [...] The changes or transformations which a character undergoes sometimes alter the entire configuration of character as it looked during the analysis of mutual relations" (BAL, 2009, p. 127).
}

Jangada | nr. 11, jan/jun, 2018 | ISSN 2317-4722 131 | Pág ina 
Arthur merece destaque não somente por trabalhar no armazém e ser o responsável por fornecer os mantimentos para a Sra. Poulter, mas também por entender que o ato de preparar alimentos, aparentemente rotineiro e banal, transcende os fenômenos químicos e físicos inerentes, afinal, não nos alimentamos somente para suprir nossas necessidades energéticas, mas também para valorizarmos essa atividade tida para muitos ultimamente como uma forma de terapia: o ato inevitavelmente envolve escolhas, preparo e rituais, ganhando o status de ação cultural. Assim, é Arthur na família Brown quem demonstra interesse por sabores desde o início da narrativa. Vejamos o seguinte excerto (retirado do capítulo "Waldo"):

-Arthur e eu vamos trocar anedotas para abafar o trovão - a Sra. Feinstein prometeu.

-Isso é torrada de canela de verdade? - Arthur perguntou, se servindo até dois ou três dedos e colocando-os amanteigados em sua boca ${ }^{15}$ (WHITE, 1974, tradução minha).

Fica nítido o interesse de Arthur pela torrada de canela oferecida no chá na casa dos Feinstein. Já no capítulo “Arthur”, o mesmo trecho, com uma descrição mais elaborada:

Quando o chá veio, e a chuva, quando eles estavam todos sentados em volta atrás de janelas bombardeadas de chuva, comendo a torrada de canela amanteigada e trocando anedotas, Arthur soube como retratar o que algumas pessoas consideravam sua personalidade agressiva. Ele soube como lamber seus dedos amanteigados com a delicadeza exigida. O mais delicioso de tudo, porque mais aparente, eram as histórias que a Sra. Feinstein tinha para contar da Europa. Ele conseguia ver as luzes das cidades prescritas como os frascos na vitrine da farmácia. Ele conseguia cheirar as florestas da Rússia que a Sra. Feinstein havia visitado com uma tia ${ }^{16}$ (WHITE, 1974, tradução minha).

\footnotetext{
${ }^{15}$ No original: "Arthur and I shall exchange anecdotes to drown the thunder," Mrs Feinstein promised. "Is this real cinnamon toast?" Arthur asked, helping himself to two or three fingers and stuffing them buttery into his mouth" (WHITE, 1974, p. 111).

${ }^{16}$ In the original: "When the tea came, and the rain, when they were all sitting round behind rain-pelted windows, eating the buttery cinnamon toast and exchanging anecdotes, Arthur knew how to retract what some people considered his aggressive personality. He knew how to lick his buttery fingers with the daintiness required. Most delicious of all, because most apparent, were the tales Mrs Feinstein had to tell of Europe. He could see the lights of the prescribed cities like the bottles in a chemist's window. He could smell the forests of Russia which Mrs Feinstein had visited with an aunt (WHITE, 1974, p. 245).
} 


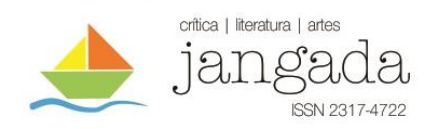

Observamos a maestria de White em trabalhar com as duas oposições narrativas (e isso permeia os dois grandes blocos da história). No caso de Arthur, o ato de comer transcende a vida deles em Sydney e promove uma viagem de pensamentos. Na imaginação de Arthur, ele vive experiências sensoriais (da visão, do olfato) desencadeadas pelo paladar (com o chá e as torradas amanteigadas de canela), fazendo a comparação do prazer sentido não somente pela alimentação, mas pela socialização, pelo compartilhamento de histórias, sem esquecer, contudo, de suas "boas maneiras", afinal, ele estava visitando a casa de Dulcie. O interesse genuíno de Arthur é o que ganha o leitor já nessa breve comparação de trechos (no capítulo "Waldo", a ênfase está nos diálogos).

Quando crianças, Waldo narra uma certa preferência dos pais por Arthur (não podemos esquecer que o ponto de vista nesta cena é de Waldo, então, desconfiamos sempre de seus posicionamentos), mas que não teve futuro porque, de fato, Arthur parecia predestinado à cozinha, apesar de ter demonstrado facilidade com os números (a ponto de ajudar Waldo na escola). Segundo a mãe,

[...] era uma espécie de gênio esperando para se revelar. Mas o Papai não estava decepcionado. Waldo muito menos. Waldo não acreditava ser possível ter mais de um gênio na volta.

Arthur certamente nasceu com seu dom para os números. Ele não precisava pedir ajuda com pesos ou medidas. Ele também gostava de lidar com a manteiga e o pão, e finalmente até a fazê-los ele mesmo. O Papai estava insatisfeito. Ele disse que não era nada para um menino, mas a Mamãe aprovava, como se a cabeça de Arthur para os números não fosse suficiente; ela parecia estar tentando transformar o preparo da manteiga e do pão em uma espécie de rito solene.

Nas ocasiões em que ele pedia se ele também poderia fazer a manteiga ou amassar o pão, Waldo ouvia: - Não. Isso é algo para Arthur. Ele tem um dom particular para isso.

Uma vez Arthur, que estava observando o leitelho jorrar de seus dedos, riu e disse: - É minha vocação, não é, Mamãe?

Waldo tinha mais ciúmes daquela palavra do que do privilégio de Arthur. Ele se perguntava de onde ele havia tirado aquilo. Porque as palavras não estavam na linha de Arthur. Era Waldo quem as colecionava, como selos ou moedas. Ele fazia listas delas. Ele as rolava em sua boca como pedras 


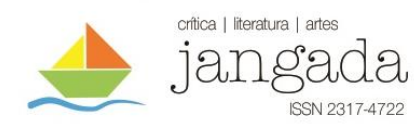

polidas. Então Arthur foi e pôs em ação essa coisa de vocação dele ${ }^{17}$ (WHITE, 1974, tradução minha).

Logo, uma das atividades essenciais de Arthur (ou melhor, sua vocação) na narrativa se torna a produção de pão caseiro e de manteiga, e chamamos a atenção novamente para o tom ritualístico e sagrado que essas atividades adquirem em The Solid Mandala. A partir desse trecho, percebemos o quanto de incômodo isso causa em Waldo (e daí a ressalva quanto aos comentários da narração deste capítulo): esse ódio inveterado a Arthur e a suas atividades culinárias reaparece em seguida, durante suas primeiras conversas com Dulcie. Waldo faz uma comparação com algo muito desagradável, em resposta à filosofia de simplicidade de vida defendida pela menina judia:

Eu não vou. Eu vou trabalhar. Você sempre pode viver de forma simples, mas bem, se você quer.

Soava tão feio e sano que sua garganta se contraiu como acontecia algumas vezes quando ele entrava na cozinha e cheirava uma fornada do pão de Arthur. Ele estava contente por não ter de responder a Dulcie ${ }^{18}$ (WHITE, 1974, tradução minha).

Percebemos o tom extremamente negativo atribuído por Waldo às fornadas de pão produzidas (mas principalmente para quem as produz). Outro trecho apresentado a seguir evidencia a caracterização física de Arthur e, novamente, com adjetivos um tanto pejorativos: "Arthur estava na cozinha mexendo a massa para uma fornada de pão. Seus ombros circundavam a bacia. Seu cabelo em chamas. Os pedaços de massa com os quais suas mãos

\footnotetext{
${ }^{17}[\ldots]$ Arthur was some kind of genius waiting to disclose himself. But Dad was not deceived, Waldo even less. Waldo didn't believe it possible to have more than one genius around. Arthur was certainly born with his gift for figures. He did not need coaxing to help out with weights and measures. He liked also to fiddle with the butter and the bread, finally even to make them himself. Dad was disgusted. He said it was nothing for a boy, but Mother approved, as though Arthur's head for figures were not enough; she seemed to be trying to turn the butter-making and bread-baking into some sort of solemn rites. On occasions when he asked whether he too might squeeze the butter or knead the dough, Waldo was told: "No. That's something for Arthur. He has a particular gift for it." Once Arthur, who was watching the buttermilk gush out from between his fingers, laughed and said: "It's my vocation, isn't it, Mother?" Waldo was more jealous of that word than he was of Arthur's privilege. He wondered where he had got it from. Because words were not in Arthur's line. It was Waldo who collected them, like stamps or coins. He made lists of them. He rolled them in his mouth like polished stones. Then Arthur went and sprang this vocation thing of his (WHITE, 1974, p. 35-36).

18“'I shan't. I shall work. You can always live simply, but well, if you want to." It sounded so plain and sane his throat contracted as it did sometimes on his going into the kitchen and smelling an ovenful of Arthur's bread. He was glad he didn't have to answer Dulcie (WHITE, 1974, p. 96).
}

Jangada | nr. 11, jan/jun, 2018 | ISSN 2317-4722 134 | Pá g in a 


\section{1 jangada}

estavam pendentes as fazia parecer horríveis - emaranhadas, ou leprosas ${ }^{19}$ ". De fato, as imagens associadas com o trabalho com a massa de pão, que naturalmente é pegajosa (formando teias e sendo "leprosa"), sinalizam todo o ódio de Waldo neste capítulo, mas que parece injustificado, pois Waldo também se alimenta desse pão feito pelo próprio irmão, conforme demonstra outro trecho:

Arthur estava agora se preparando para entrar e fazer o pão e o leite, levemente adocicado, que tranquilizava a agitação dos estômagos acidulantes depois das caminhadas. Ele servia em tigelas de pudim, e eles pegariam seus potes e comeriam deles em qualquer quarto que eles quisessem estar. Algumas vezes eles veriam que haviam escolhido o mesmo quarto, ou Arthur havia caído no de Waldo, não havia escapatória, não do glup glup do pão e leite de outro. Quanto mais alto Arthur engolia, o mais engenhosamente Waldo gerenciava sua colher. Ele conseguia sentir seus dentes, em autodefesa, movendo como os falsos de alguma mulher super refinada em uma lanchonete de mulheres de negócios, embora seus próprios dentes, ele sabia, ainda eram fortes como pregos, e quando sozinho, e não havia necessidade de mostrar um exemplo, ele morderia a comida como um animal, seu prazer aumentando com a violência do ato físico.

$\mathrm{Na}$ companhia de seu irmão ele se sentia compelido a esfregar sua boca, e dobrava seu lenço, e dizia: - Se você conseguisse se ouvir comendo pão e leite você ouviria a maré desaguando em um esgoto.

Arthur não se importava. Ele muito raramente se importava com o que as pessoas diziam ${ }^{20}$ (WHITE, 1974, tradução minha).

\footnotetext{
${ }^{19}$ No original: "Arthur was in the kitchen mixing dough for a batch of bread. His shoulders rounded over the bowl. His hair alight. The tatters of dough with which his hands were hung made them look dreadful - webbed, or leprous" (WHITE, 1974, p. 147).

${ }^{20}$ Arthur was now preparing to go in and make that bread and milk, faintly sweetened, which soothed away the flapping of acidulous stomachs after walks. He used to serve it out in pudding basins, and they would take their basins and eat from them in whichever room they wanted to be. Sometimes they would find they had chosen the same room, or Arthur had flopped down in Waldo's, there was no escaping, nor from the glup glup of someone else's bread and milk. The louder Arthur glupped, the more ingeniously Waldo managed his spoon. He could feel his teeth, in self-defence, moving like the false ones of some over-refined female in a business-women's luncheonette, though his own teeth, he knew, were still sound as nails, and when alone, and there was no need to set an example, he would worry food like an animal, his pleasure increasing with the violence of the physical act. In his brother's company he felt compelled to wipe his mouth, and fold his handkerchief, and say: "If you could listen to yourself eating bread and milk you would hear the tide turning in a sewer." Arthur didn't mind. He very rarely cared what people said" (WHITE, 1974, p. 204-205).
} 
As descrições dos rituais da alimentação permeiam o romance. Ganha destaque aqui o processo de envelhecimento do personagem também sendo comparado com a desenvoltura já não mais tão vigorosa na fabricação do pão caseiro. Na cena, há um clima de tensão, haja vista o pedido de Waldo para que Arthur não se encontre mais com a Sra. Poulter, de certo modo "quebrando" toda aquela conexão criada por meio da cozinha:

O pão, que era sua vocação, havia começado a ficar difícil. A massa longa, fibrosa estava se atando nas extremidades de seus dedos.

-Então - acrescentou ele - a Sra. Poulter é minha amiga.

Waldo riu alto por entre o suor que estava saltando de seu rosto.

-Oh sim! - ele riu. - Assim estão dizendo! Esse é o ponto. Qualquer que seja a verdade, está além disso. Você não vê? E você está nos degradando! Mesmo se fosse muito cabeça dura para se magoar pelo que as pessoas pensam e dizem.

Quando repentinamente o pão ficou mais simples. Arthur havia libertado seus dedos.

-A Sra. Poulter - disse ele - diz que não devemos ir mais juntos. $\mathrm{O}$ marido dela ficou ofendido.

Se você conseguisse acreditar que as pessoas eram tão simples, e Waldo não conseguia completamente, mas esperava. A dignidade é ganha tão arduamente, e perdida tão facilmente.

-Bom, se vocês decidiram assim, entre vocês - disse ele parabenizo você, Arthur.

Isso o fez se sentir como o irmão mais velho de Arthur, o que na verdade ele havia se tornado.

Enquanto o rosto de menino grande de Arthur estava consolado por este simples arranjo. Ele continuou simplesmente a encher as latas untadas com a massa ${ }^{21}$ (WHITE, 1974, tradução minha).

\footnotetext{
${ }^{21}$ The bread, which was his vocation, had begun to grow difficult. The long, stringy dough was knotting at the ends of his fingers. "Then," he added, "Mrs Poulter is my friend." Waldo laughed out loud through the sweat which was bouncing off his face. "Oh yes!" he laughed. "So they're saying! That's the point. Whatever the truth, that's beside it. Don't you see? And you're degrading us! Even if you're too thickwitted to be hurt by what other people think and say." When suddenly the bread grew simpler. Arthur had freed his fingers. "Mrs Poulter," he said, "says we mustn't go together any more. Her husband got offended." If you could believe that people were so simple, and Waldo couldn't quite, but hoped. Dignity is too hard won, and lost too easily. "Well, if you've decided it like that, between yourselves," he said, "I congratulate you, Arthur." It made him feel like Arthur's
}

Jangada | nr. 11, jan/jun, 2018 | ISSN 2317-4722 136|Página 
De fato, a sensibilidade de toda a cena, que aparece no capítulo "Waldo", está justamente no acompanhamento das fases do preparo do pão: as coisas tornam-se mais simples à medida que a massa também se desgruda dos dedos de Arthur (é como se uma epifania acontecesse, pois Arthur de fato parece se transformar no "irmão mais velho" na cena).

No capítulo "Arthur", há a descrição da mesma cena - o anúncio do rompimento da relação entre a Sra. Poulter e Arthur -, mas o tom da narrativa é bem diferente:

Era uma coisa boa talvez que Arthur estivesse fazendo o pão. Aquilo por si só poderia ter ajudado a estabelecer sua honestidade se a Sra. Poulter mesmo não havia contribuído.

- A Sra.Poulter decidiu - ele foi capaz de contar a Waldo enquanto ele dobrava e redobrava a massa ${ }^{22}$ (WHITE, 1974, tradução minha).

Notamos que a dobra e a redobra da massa se torna algo que favorece o comportamento de Arthur ao se defrontar com o irmão, explicando que a decisão não havia sido tomada apenas de um lado, mas em comum acordo. O fato de Arthur ser reconhecido como necessário para manter não apenas a Sra. Allwright, mas também a sua própria família (então composta apenas de Waldo, agora que os gêmeos já estavam mais idosos) talvez seja motivo de mais ira por parte de Waldo, conforme atesta o seguinte trecho (retirado do capítulo "Waldo"):

Arthur continuou notavelmente ativo. Depois da morte de Allwright em 1951, a viúva o havia mantido. Ele era necessário a ela, especialmente para as entregas, e porque ele lembrava os preços que ela esquecia: em casa como sempre ele amassava o pão três vezes por semana. E fazia a manteiga duas vezes, de qualquer vaca. Waldo nunca lembrava os nomes, o número na série. Ele odiava vacas ${ }^{23}$ (WHITE, 1974, tradução minha).

elder brother, which in fact he had become. While Arthur's overgrown-boy's face was consoled by this simple arrangement. He went on simply to fill the greased tins with dough (WHITE, 1974, p. 148).

${ }^{22}$ It was a good thing perhaps that Arthur was mixing the bread. That on its own might have helped establish his honesty if Mrs Poulter herself had not contributed. "Mrs Poulter has decided," he was able to tell Waldo as he folded and re-folded the dough (WHITE, 1974, p. 267).

${ }^{23}$ No original: "Arthur continued remarkably active. After the death of Allwright in 1951, the widow had kept him on. He was necessary to her, especially for the deliveries, and because he remembered the prices she forgot.

Jangada | nr. 11, jan/jun, 2018 | ISSN 2317-4722 137 | Pá g ina 
O final do trecho denota mais uma vez o nível de recalque de Waldo não somente para com os animais, mas para com todo o universo que o cerca. As filosofias das personagens em relação ao hábito, por exemplo, também têm como referentes as atividades praticadas na cozinha. Segundo Waldo: "O hábito nos momentos mais fracos é tranquilizante como pão e leite adoçado ${ }^{24 ”}$ (WHITE, 1974, tradução minha). No trecho seguinte, retirado do capítulo "Arthur", o personagem homônimo divaga sobre sua vida, mas Waldo (que a certa altura da narrativa já evidencia sinais de paranoia) é quem comenta sobre as possibilidades alimentícias dos gêmeos (algumas herdadas da mãe deles), com um tom de prescrição e visando à longevidade:

No começo ele havia se perguntado como preencher o tempo. Claro que havia o pão e o leite que eles comiam, e nos domingos o hábito do pão de salmão que eles haviam herdado da Mamãe. Eles comiam normalmente coisas fervidas, porque Waldo havia ordenado.

- Comida fervida previne úlceras - dizia ele - e tanto quanto qualquer outra coisa ajuda a garantir a longevidade.

E havia a fabricação da manteiga além disso, e do pão. Arthur limpava as lamparinas, uma atividade que ele associava com aquela de bater ou assar, o resultado tão lúcido ${ }^{25}$ (WHITE, 1974, tradução minha).

Arthur finaliza seus pensamentos fazendo uma analogia interessante entre a limpeza das lâmpadas (e a lucidez advinda) com a sua atividade de preparo do pão e da manteiga (que conferia a ele, de certo modo, uma lucidez acerca de sua missão e de seu dom). Isso novamente parece ter relação com o posicionamento dele na cena em que discute com Waldo acerca do fim de suas aparições em público com a Sra. Poulter: ao fazer o pão e a manteiga, ele obtinha segurança e, provavelmente, lucidez para lidar com qualquer tipo de tópico.

\footnotetext{
At home as usual he baked the bread three times a week. And made the butter twice, from whichever cow. Waldo never remembered the names, the number in the series. He hated cows" (WHITE, 1974, p. 203).

${ }^{24}$ No original: "Habit in weaker moments is soothing as sugared bread and milk" (WHITE, 1974, p. 204).

${ }^{25}$ No original: "In the beginning he had wondered how to fill the time. Of course there was the bread and milk they ate, and on Sundays the salmon-loaf habit which they had inherited from Mother. They ate mostly boiled stuff, because Waldo had ordained. "Boiled food prevents ulcers," he said, "and as much as anything else helps ensure longevity." And there was the butter-making besides, and bread. Arthur used to clean the lamps, an activity he associated with that of churning or baking, the outcome so lucid (WHITE, 1974, p. 290).
}

Jangada | nr. 11, jan/jun, 2018 | ISSN 2317-4722 138| Pág ina 
Se anteriormente tínhamos a impressão de que a chegada da Sra. Poulter representou algo importante em todas as relações do romance, o seguinte trecho, retirado do capítulo “Arthur", evidencia o motivo da preocupação (ou dos ciúmes, de certo modo) da mãe dos gêmeos. Se Arthur não demonstrava qualquer talento para a música (pois seus pais haviam investido nesse tipo de formação, mas sem resultados satisfatórios), então, a partir dessa desistência, que a deixou um tanto pesarosa, a fabricação do pão e da manteiga se tornou uma forma de aproximação de ambos, ou, como explicitado no excerto, a sua "conspiração":

Em vez disso, eles entraram mais profundamente na conspiração deles da manteiga e do pão. Somente ela e Arthur deviam entender o mistério que eles tinham de celebrar. Arthur estava muito contente em adotar os ritos que ela impunha nele. À luz da lamparina ele e a Mamãe se tornaram o próprio círculo fechado deles na cozinha ${ }^{26}$ (WHITE, 1974, tradução minha).

Neste trecho, percebemos que a chegada da Sra. Poulter representa um divisor de águas não apenas na vida de Arthur, mas podemos dizer em toda a narrativa.

\section{CONCLUSÃO}

A partir dessa breve análise dos excertos que apresentam a cozinha como um cenário importante na narrativa de The Solid Mandala, de Patrick White, pudemos perceber que essa relação entre literatura e culinária se faz presente, e não é por acaso. A partir da própria preferência do autor, essas relações são desenvolvidas no percurso narrativo de um dos gêmeos, Arthur, em oposição a Waldo e aos demais personagens da trama. A cozinha não é mais apenas um dos cenários da história: ela carrega significados. É onde a relação de amizade e compartilhamento de mistérios e de rituais e de visões de mundo acontece entre Arthur e a Sra. Poulter; é onde Arthur consegue estabelecer uma relação de proximidade e cumplicidade com sua mãe, durante sua "conspiração de manteiga e pão"; e é onde histórias são compartilhadas de momentos históricos importantes vividos em outras paisagens e que despertam o interesse de Arthur em conhecer o mundo (por meio de sabores e também da literatura).

\footnotetext{
${ }^{26}$ Instead, they entered deeper into their conspiracy of butter and bread. Only she and Arthur were to understand the mystery they had to celebrate. Arthur was only too glad to adopt the rites she imposed on him. By lamplight he and Mother became their own closed circle in the kitchen. This development gave Arthur Brown a satisfaction more intense than any he experienced before the coming of Mrs Poulter (WHITE, 1974, p. 232).
}

Jangada | nr. 11, jan/jun, 2018 | ISSN 2317-4722 139 | Pá g ina 


\section{1 jangada}

Tendo em vista as personagens femininas do romance, conseguimos vê-las como responsáveis pelo "sacramento da comida" ("sacrament of food"). A Sra. Poulter tem o comportamento mais evidente relacionado à religião, porque o narrador deixa isso explícito. No entanto, pensamos também nessa possibilidade de interpretação aplicada à Sra. Feinstein, ao oferecer o chá com as torradas para Arthur (isto é, a ideia de ela ser a responsável por alimentá-lo). O mesmo em relação à mãe, Anne Quantrell, que passa ao filho o ritual da fabricação do pão e da manteiga, transformando-o em uma "vocação" (termo carregado semanticamente, remetendo aqui à religiosidade e à espiritualidade de Arthur).

Enfocando o percurso narrativo de Arthur, percebemos que ele assume o "sacramento da comida" ao sustentar seu irmão Waldo com os produtos do seu ritual, apesar de ser constantemente alvo de sua ira. Se temos elementos de transcendência a todo momento no modo de vida de Arthur, conseguimos aplicar essa filosofia na relação estabelecida entre cozinha e literatura: duas formas de arte que possuem funções igualmente importantes. Se uma alimenta o corpo físico, fornecendo nutrientes para que desempenhemos nossas tarefas diárias, a outra alimenta nossa alma, nosso intelecto, nossa sede de emoções e de reflexões. A cozinha nos alimenta para que tenhamos força de alimentar nossas esperanças de ver um mundo mais justo e emotivo. Se Patrick White "disse quase tudo o que ele queria, vemos que ele expõe um apelo por esperança, usando a imagem da mandala e dos valores atrelados nisso (a importância de unir os elementos para melhor compreender o todo ${ }^{27 "}$ (STEFANI, 2011, p. 28).

\section{REFERÊNCIAS BIBLIOGRÁFICAS}

BAL, Mieke. Narratology: Introduction to the Theory of Narrative. $3^{\text {rd }}$. ed. Traduzido por Christine Van Boheemen. Toronto: University of Toronto Press, 2009.

MARR, David. Patrick White: a Life. Sydney: Vintage, 1995.

NEWMARK, Peter. A Textbook of Translation. New York: Prentice Hall, 1988.

\footnotetext{
${ }^{27}$ No original: "said almost everything that he wanted, we see that he exposes a plea for hope, using the image of the mandala and of the values entangled in that (the importance of uniting the elements to better understand the whole) (STEFANI, 2011, p. 28).
} 


\section{1 jangada}

STEFANI, Monica. The Translation of Patrick White's The Solid Mandala into Brazilian Portuguese: an Analysis Based on Social, Historical and Cultural Aspects. 2016. 314 f. Tese (Doutorado em Letras) - Instituto de Letras, UFRGS, Porto Alegre.

. 'You are what you read': intertextual relations in Patrick White's The Solid Mandala.

2011. 118 f. Dissertação (Mestrado em Letras) - Instituto de Letras, UFRGS, Porto Alegre.

WHITE, Patrick. The Solid Mandala. Sydney: Penguin, 1974. 